\title{
Efficiency Comparison of Different DC-DC Converter Architectures for a Power Supply of a LiDAR System
}

\author{
Ruben E. Figueiredo ${ }^{1}$, Vitor Monteiro' ${ }^{1}$, Jose A. Afonso ${ }^{2}$, J. G. Pinto ${ }^{1}$, \\ Jose A. Salgado ${ }^{1}$, Luiz A. Lisboa Cardoso ${ }^{1}$, \\ Miguel Nogueira ${ }^{3}$, Aderito Abreu ${ }^{3}$, Joao L. Afonso ${ }^{1}$ \\ ${ }^{1}$ ALGORITMI Research Centre, University of Minho, Guimarães, Portugal \\ ${ }^{2}$ CMEMS-UMinho Center, University of Minho, Guimarães, Portugal \\ ${ }^{3}$ Bosch Car Multimedia Portugal, S.A. Rua do Barrio de Cima, nº1, 4705-820 Braga, Portugal \\ ruben.figueiredodalgoritmi.uminho.pt
}

\begin{abstract}
LiDAR (Light Detection And Ranging) is a technology used to measure distances to objects. Internally, a LiDAR system is constituted by several components, including a power supply, which is responsible to provide the distinct voltage levels necessary for all the components. In this context, this paper presents an efficiency comparison of three different DC-DC converter architectures for a LiDAR system, each one composed of three DC-DC converters: in parallel; in cascade; and hybrid (mix of parallel and cascade). The topology of the adopted integrated DC-DC converters is the synchronous buck SwitchedMode Power Supply (SMPS), which is a modified version of the basic buck SMPS topology. Three distinct SMPSs were considered: LM5146-Q1, LM5116, and TPS548A20RVER. These SMPSs were selected according to the requirements of voltage levels, namely, $12 \mathrm{~V}, 5 \mathrm{~V}$, and $3.3 \mathrm{~V}$. Along the paper, the principle of operation of the SMPSs is presented, as well as the evaluation results obtained for different operating powers, allowing to establish a comprehensive efficiency comparison.
\end{abstract}

Keywords: LiDAR, DC-DC Converters, Efficiency Comparison, Synchronous Buck, Switched Mode Power Supply.

\section{Introduction}

Autonomous vehicles are identified as the main booster in terms of future intelligent transport in smart and sustainable cities [1]. Within this context, LiDAR (Light Detection and Ranging) is one of the key sensing technologies required to enable partial or fully autonomous driving [2]. Specifically, LiDAR is an active remote sensing method that works on the same principle of sonar, but using laser pulses to build a 3D model of the environment around. Internally, a LiDAR system is constituted by several parts such as a laser source capable of transmitting pulsed or continuous light, a low noise highspeed receiver capable of detecting and processing the reflected light beam and a low power controller unit, where the power supply is a common system to all the parts, 
which must guarantee the proper voltage and power levels. Concretely, the power supply is constituted by DC-DC power converters, each one with specific output voltage levels.

DC-DC power converters, in the perspective of an integrated solution, have increasingly been identified as extremely important, and arisen as an interesting and valid solution to the growing need for various voltage levels. The application of solutions based on integrated DC-DC converters presents a set of significant advantages over the solutions implemented using discrete DC-DC converters (e.g., less volume, weight and cost, and more robustness), mainly for automotive applications [3], such as LiDAR systems. It is also important to highlight that integrated DC-DC converters do not require large resources in terms of additional passive components, also allowing to increase the reliability and significantly simplifying their assembly and testing, when embedded in the target application.

In [4], it is proposed an innovative DC-DC power converter based on an integrated capacitive step-up structure, specifically dedicated to a LiDAR system in automotive applications. This converter operates from an input voltage of $12 \mathrm{~V}$, allowing to supply the load with $70 \mathrm{~V}$, with a maximum operating power of $320 \mathrm{~mW}$. In [5], it is proposed the design and development of a power supply based on a DC-DC power converter for a high-power diode laser, for application on a LiDAR, which is part of an unmanned aerial vehicle. A new perspective of digital control, based on a variable-frequency with a multi-megahertz characteristic, is proposed in [6] for the application on a boost converter used on a LiDAR, presenting as main contribution the possibility to improve the efficiency, even when operating with sudden power variations.

Regarding general DC-DC power converters, several reviews can be found in the literature $[7,8]$, including DC-DC converters for very specific applications $[9,10]$. However, for the most part, the presented solutions use many discrete components in the implementation of the DC-DC converters, not being the most beneficial for applications as LiDAR systems. In addition, in LiDAR systems, different architectures can be optionally used by associating distinct DC-DC power converters, when there is a need to supply different output voltages. For example, it is possible to identify in the literature architectures with parallel DC-DC converters (i.e., single-input multiple-output, SIMO), cascade DC-DC converters (i.e., the output of a converter is the input of the next one) and DC-DC converters with a hybrid association (i.e., combining parallel and cascade structures) [11][12].

In this context, this paper presents a comparison between three different architectures for the power supply of a LiDAR, by reorganizing the same DC-DC converters in the three different architectures: (i) an architecture with all of them in parallel; (ii) an architecture with the three DC-DC converters linked in cascade; and (iii) a hybrid architecture, with two DC-DC converters connected in parallel to the output of the third one. The topology adopted in the scope of this paper is the synchronous buck Switched-Mode Power Supply (SMPS), which is a modified version of the conventional buck converter SMPS, in which the diode is replaced by a second power switch (MOSFET), minimizing the diode conduction losses and thus improving the conversion efficiency [16]. The LiDAR systems requires a total power of $50 \mathrm{~W}$ for the three different voltages values according to its function and divided as: $17 \mathrm{~W}$ at $3.3 \mathrm{~V}, 5 \mathrm{~W}$ at 
$5 \mathrm{~V}$, and $28 \mathrm{~W}$ at $12 \mathrm{~V}$. In terms of the value of the input voltage for the converters, the maximum voltage to be considered is $65 \mathrm{~V}$, which is a requisite of the LiDAR system. For this purpose, the following models of DC-DC converters were considered: (i) the switching controller LM5146-Q1 [13]; (ii) the switching controller LM5116 [14]; (iii) the switching regulator TPS548A20RVER [15].

As the main contribution of this paper, it can be highlighted a comparative analysis, in terms of efficiency, among the three power supply architectures, all respecting the voltage limits of each DC-DC converter. The efficiency was determined for the highest voltage value possible at the input of each converter and with the maximum power required, usually, the most critical condition for real systems.

The rest of the paper is organized as follows. Section 2 presents the synchronous buck converter topology used by the selected converter chips. Section 3 describes the architectures proposed in this study, and Section 4 presents the main results obtained with each architecture, as well as the energy efficiency comparison for the three cases. Finally, Section 5 presents the main conclusions of the paper.

\section{Synchronous Buck SMPS Topology}

The synchronous buck SMPS topology is represented in Fig. 1, which allows to obtain a regulated output voltage lower than the input voltage. As shown, it is mainly constituted by two power MOSFETs, an input capacitor $\mathrm{C} 1$, an output inductor L1, and an output capacitor $\mathrm{C} 2$.

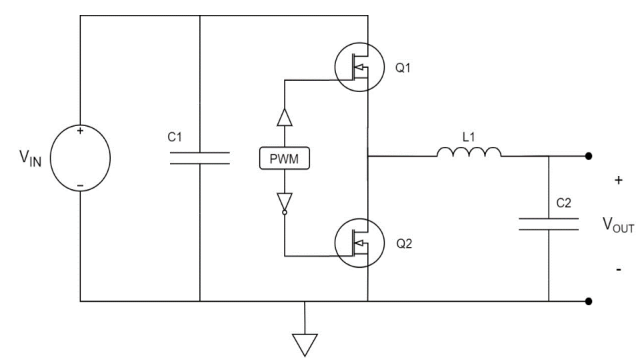

Fig. 1. Simplified schematic of the synchronous buck converter.

The average voltage at the output of the synchronous buck converter is directly influenced by the duty-cycle applied to the MOSFET gate terminals. Besides, some other important parameters, such as the current ripple, the voltage ripple and the minimum and maximum current through the inductor are dependent on the frequency and dutycycle [17]. The synchronous buck converter has two operating modes. In mode 1, Q1 is 'on', while Q2 is 'off', therefore, the current in the inductor increases. In mode 2, Q2 is 'on', while Q1 is 'off', providing a path for the energy stored in the inductor to flow through the load. The two MOSFETs (Q1 and Q2) are alternately switched according to the PWM signal generated by a controller IC [18].

Comparatively to the non-synchronous buck SMPS topology, the synchronous buck topology has generally less power dissipation, resulting in a higher efficiency [17], 
since the voltage-drop across the low-side MOSFET (Q2) can be lower than the voltage-drop across the diode, in the case of the non-synchronous topology.

\section{$3 \quad$ Architectures in Comparison}

Automotive applications, such as the considered LiDAR system, require high efficient DC-DC conversions. In the particular application scenario of this study, the available input voltage ranges from $15 \mathrm{~V}$ to $65 \mathrm{~V}$, higher than the required output voltages, $3.3 \mathrm{~V}$, $5 \mathrm{~V}$, and $12 \mathrm{~V}$. Because of that, SMPSs (topology described at section 2) were used to step down the input voltage to the intended values. Fig. 2 presents the two standard architectures, parallel and cascade, while Fig. 3 presents the four possible hybrid architectures that could, in principle, also be adopted for the power supply satisfying this application.

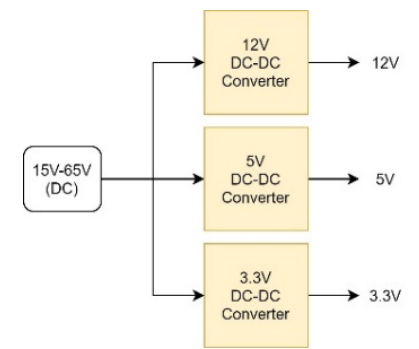

(a)

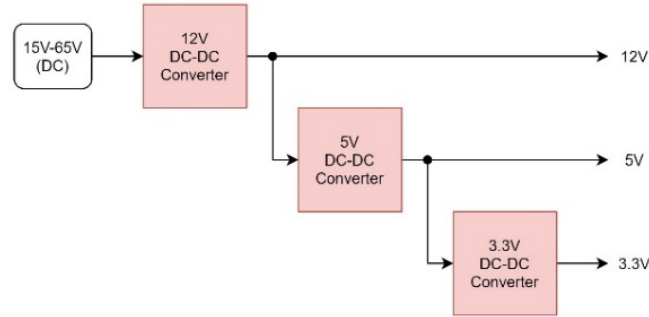

(b)

Fig. 2. Standard architectures: (a) Parallel (SIMO); (b) Cascade.

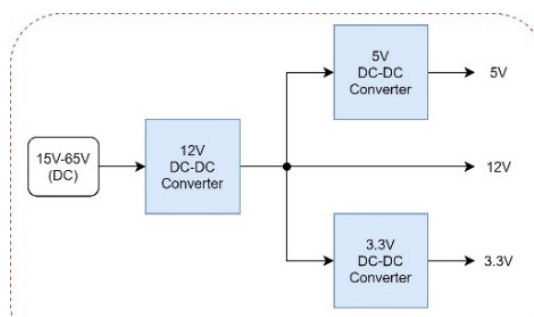

(a)

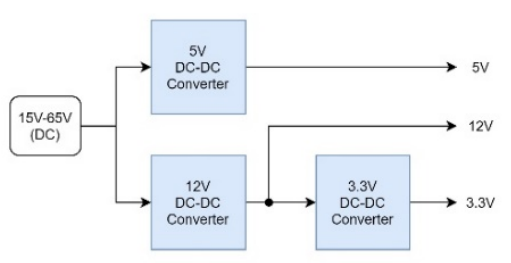

(c)

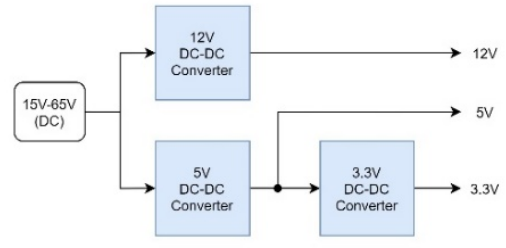

(b)

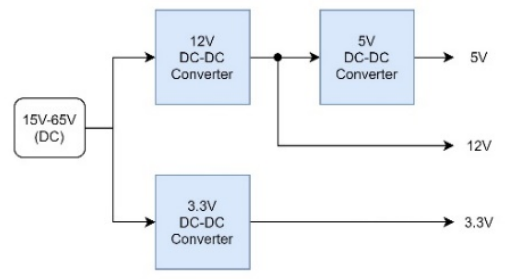

(d)

Fig. 3. Hybrid variant architectures. 
To demonstrate the methodology used in the efficiency comparison, and for the sake of simplicity, in this work only one of the hybrid variants, Fig. 3 (a), is used in the comparison with the parallel and cascade architectures, shown in Fig. 2. It was selected this architecture because it seems that it guarantees better efficiency since the voltage in the first stage is the nearest of the output voltage.

The input voltages, output voltages, output current, as well as the SMPSs used in each architecture, are presented in Table 1. LM5146-Q1 and LM5116 are switching controllers with a wide input voltage range $(5.5 \mathrm{~V}$ to $100 \mathrm{~V}$ and $6 \mathrm{~V}$ to $100 \mathrm{~V}$, respectively) and a wide adjustable output voltage $(0.8 \mathrm{~V}$ to $60 \mathrm{~V}$ and $1.215 \mathrm{~V}$ to $80 \mathrm{~V}$, respectively). TPS548A20RVER is a switching regulator with input range from $1.5 \mathrm{~V}$ to $20 \mathrm{~V}$, output voltage from $0.6 \mathrm{~V}$ to $5.5 \mathrm{~V}$ and a maximum output current of $15 \mathrm{~A}$.

Table 1. Specifications of the power supply characteristics of each architecture.

\begin{tabular}{|c|c|c|c|c|}
\hline & $\begin{array}{l}12 \text { V DC-DC } \\
\text { Converter }\end{array}$ & $\begin{array}{l}5 \mathrm{~V} \text { DC-DC } \\
\text { Converter }\end{array}$ & $\begin{array}{c}3.3 \text { V DC-DC } \\
\text { Converter }\end{array}$ & Architecture \\
\hline Input voltage & $15 \mathrm{~V}-65 \mathrm{~V}$ & $15 \mathrm{~V}-65 \mathrm{~V}$ & $15 \mathrm{~V}-65 \mathrm{~V}$ & \multirow{4}{*}{ Parallel } \\
\hline Output voltage & $12 \mathrm{~V}$ & $5 \mathrm{~V}$ & $3.3 \mathrm{~V}$ & \\
\hline Converter Chip & LM5146-Q1 & LM5146-Q1 & LM5116 & \\
\hline Output current & $2.33 \mathrm{~A}$ & $1 \mathrm{~A}$ & $5.15 \mathrm{~A}$ & \\
\hline Input voltage & $15 \mathrm{~V}-65 \mathrm{~V}$ & $12 \mathrm{~V}$ & $5 \mathrm{~V}$ & \multirow{4}{*}{ Cascade } \\
\hline Output voltage & $12 \mathrm{~V}$ & $5 \mathrm{~V}$ & $3.3 \mathrm{~V}$ & \\
\hline Converter Chip & LM5146-Q1 & LM5146-Q1 & TPS548A20RVER & \\
\hline Output Current & $4.24 \mathrm{~A}$ & $4.47 \mathrm{~A}$ & $5.15 \mathrm{~A}$ & \\
\hline Input voltage & $15 \mathrm{~V}-65 \mathrm{~V}$ & $12 \mathrm{~V}$ & $12 \mathrm{~V}$ & \multirow{4}{*}{ Hybrid } \\
\hline Output voltage & $12 \mathrm{~V}$ & $5 \mathrm{~V}$ & $3.3 \mathrm{~V}$ & \\
\hline Converter Chip & LM5146-Q1 & TPS548A20RVER & LM5146-Q1 & \\
\hline Output current & $4.22 \mathrm{~A}$ & $1 \mathrm{~A}$ & $5.15 \mathrm{~A}$ & \\
\hline
\end{tabular}

\section{$4 \quad$ Evaluation Results}

To evaluate and compare the performance of each architecture, the DC-DC converters were simulated using the WEBENCH® Power Designer software [19], in order to determine its individual efficiency at an ambient temperature of $25^{\circ} \mathrm{C}$. The efficiency was obtained for the maximum operating power required at each output voltage level, as shown in Table 2, also considering the highest possible voltage at the input, corresponding to the most critical situation. The switching frequency of each converter was selected in order to achieve the best performance. 
Table 2. Power required by the LiDAR at each voltage level.

\begin{tabular}{|c|c|}
\hline Voltage Level & Operating Power \\
\hline $3.3 \mathrm{~V}$ & $17 \mathrm{~W}$ \\
\hline $5 \mathrm{~V}$ & $5 \mathrm{~W}$ \\
\hline $12 \mathrm{~V}$ & $28 \mathrm{~W}$ \\
\hline
\end{tabular}

\subsection{Parallel Architecture}

In this architecture the DC-DC converters $(12 \mathrm{~V}, 5 \mathrm{~V}$ and $3.3 \mathrm{~V})$ share the same input voltage, ranging from $15 \mathrm{~V}$ to $65 \mathrm{~V}$, as illustrated in Fig. 2 (a).

According to the graph displayed in Fig. 4, the obtained efficiency of the $3.3 \mathrm{~V}$ DC-DC converter for an output current of $5.15 \mathrm{~A}$ and an input voltage of $65 \mathrm{~V}$ (worst case) is approximately $84.5 \%$. For the same output current, but with lower input voltages, the efficiency is higher, namely, $88 \%$ for an input voltage of $40 \mathrm{~V}$, and, approximately, $93 \%$ for an input voltage of $15 \mathrm{~V}$.

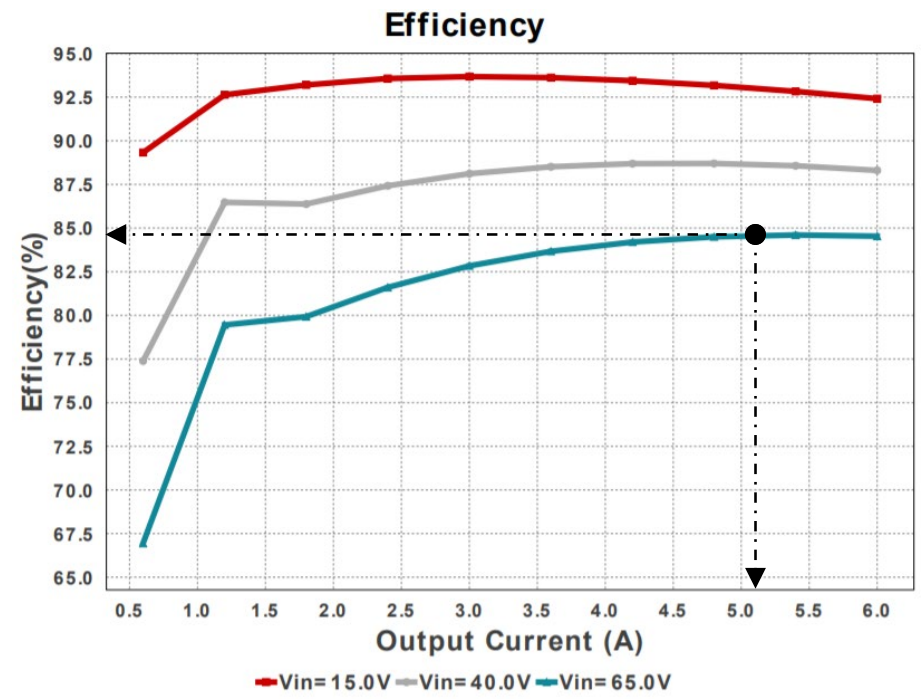

Fig. 4. Obtained efficiency regarding the output voltage level of $3.3 \mathrm{~V}$ (Parallel Architecture).

According to the graph displayed in Fig. 5, the obtained efficiency of the $5 \mathrm{~V} \mathrm{DC}$-DC converter for an output current of $1 \mathrm{~A}$ and an input voltage of $65 \mathrm{~V}$ (worst case) is approximately $75 \%$. As in the previous converter, for the same output current, with lower input voltages, the efficiency is higher, namely, $82.5 \%$ for an input voltage of $40 \mathrm{~V}$ and $92 \%$ for an input voltage of $15 \mathrm{~V}$. 


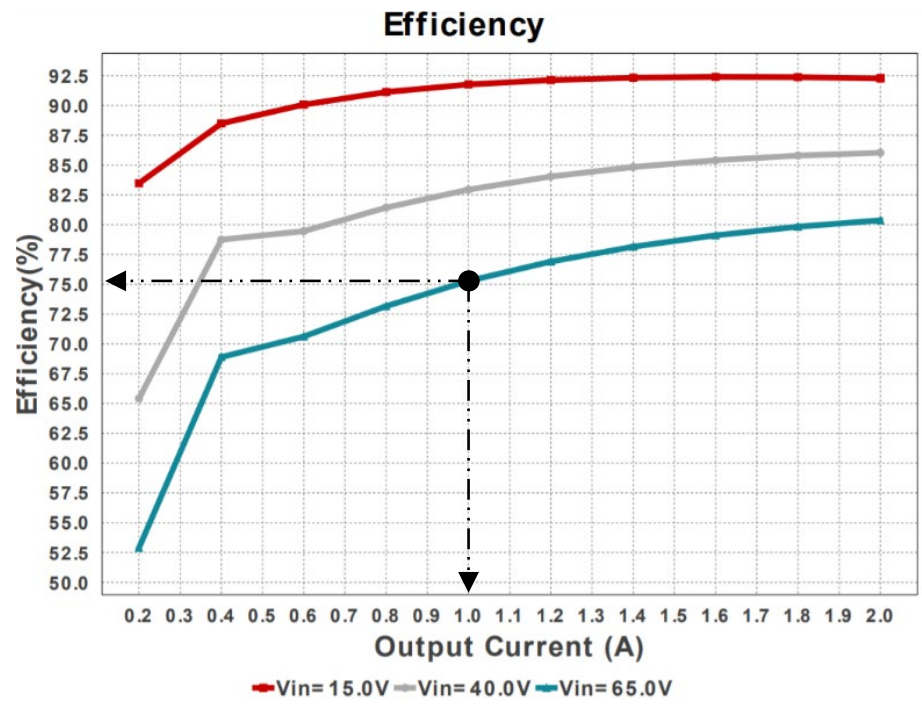

Fig. 5. Obtained efficiency regarding the output voltage level of 5 V (Parallel Architecture).

According to the graph displayed at Fig. 6, the expected efficiency of the $12 \mathrm{~V} \mathrm{DC}-\mathrm{DC}$ converter for an output current of $2.33 \mathrm{~A}$ and an input voltage of $65 \mathrm{~V}$ (worst case) is approximately $95.2 \%$. Once again, for the same output current, with lower input voltages the efficiency is higher, namely $96.2 \%$ for an input voltage of $40 \mathrm{~V}$ and approximately $98.2 \%$ for an input voltage of $15 \mathrm{~V}$.

\section{Efficiency}

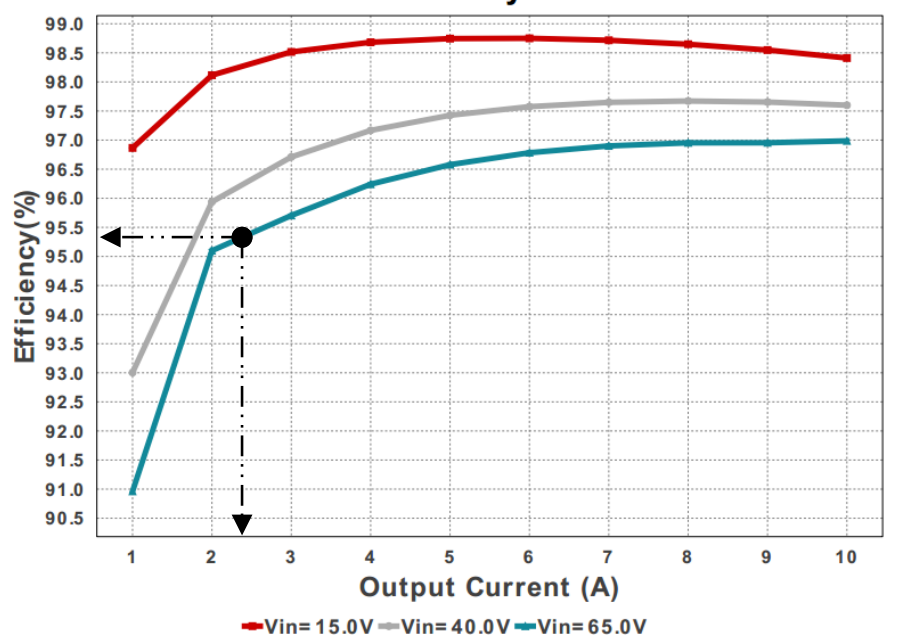

Fig. 6. Obtained efficiency regarding the output voltage level of $12 \mathrm{~V}$ (Parallel Architecture).

Therefore, the overall efficiency for the parallel architecture considering the most critical situation is: 


$$
\eta=\frac{50 W}{\frac{5 W}{0.75}+\frac{17 W}{0.845}+\frac{28 W}{0.952}}=0.8897=88.97 \%
$$

where $50 \mathrm{~W}$ is the total output power and $5 \mathrm{~W} / 0.75$ is the $3.3 \mathrm{~V} \mathrm{DC}$-DC converter input power, $17 \mathrm{~W} / 0.845$ is the $5 \mathrm{~V} \mathrm{DC}$-DC converter input power and $28 \mathrm{~W} / 0.952$ is the $12 \mathrm{~V}$ DC-DC converter input power.

\subsection{Cascade Architecture}

In this architecture the three converters are connected in cascade; therefore, the $12 \mathrm{~V}$ DC-DC converter has the input range of $15 \mathrm{~V}$ to $65 \mathrm{~V}$, the $5 \mathrm{~V}$ DC-DC converter has the input of $12 \mathrm{~V}$ and the $3.3 \mathrm{~V}$ DC-DC converter has the input of $5 \mathrm{~V}$, as illustrated in Fig. 2 (b).

According to the graph displayed at Fig. 7, the expected efficiency of the $3.3 \mathrm{~V}$ DC-DC converter $\left(E f f_{C 3.3 \mathrm{~V}}\right)$ for an output current of $5.15 \mathrm{~A}$ and an input voltage of $5 \mathrm{~V}$ is approximately $97.95 \%$.

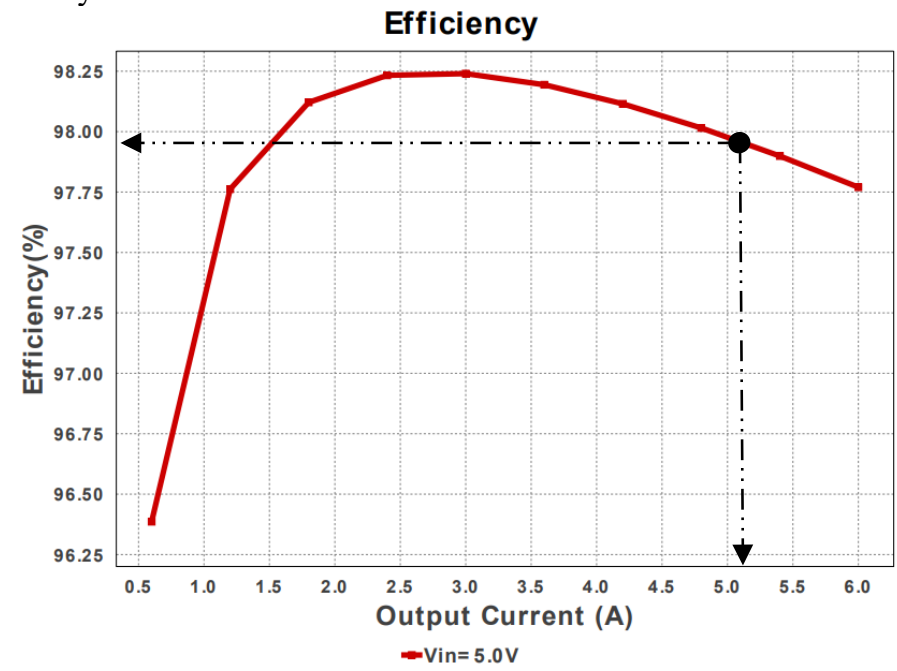

Fig. 7. Obtained efficiency regarding the output voltage level of 3.3 V (Hybrid Architecture).

The output current required at the $5 \mathrm{~V} \mathrm{DC}$-DC converter for the $5 \mathrm{~W}$ requested by the LiDAR system and to power the $3.3 \mathrm{~V}$ DC-DC converter is:

$$
\text { Iout }_{5 \mathrm{~V} \mathrm{converter}}=\frac{5 \mathrm{~W}+\frac{17 \mathrm{~W}}{E f f_{C 3.3 \mathrm{~V}}}}{5 \mathrm{~V}}=4.47 \mathrm{~A}
$$

According to the graph displayed at Fig. 8, the expected efficiency of the $5 \mathrm{~V}$ DC-DC converter $\left(E f f_{C 5 V}\right)$ for an output current of $4.47 \mathrm{~A}$ and an input voltage of $12 \mathrm{~V}$ is approximately $97.9 \%$. 


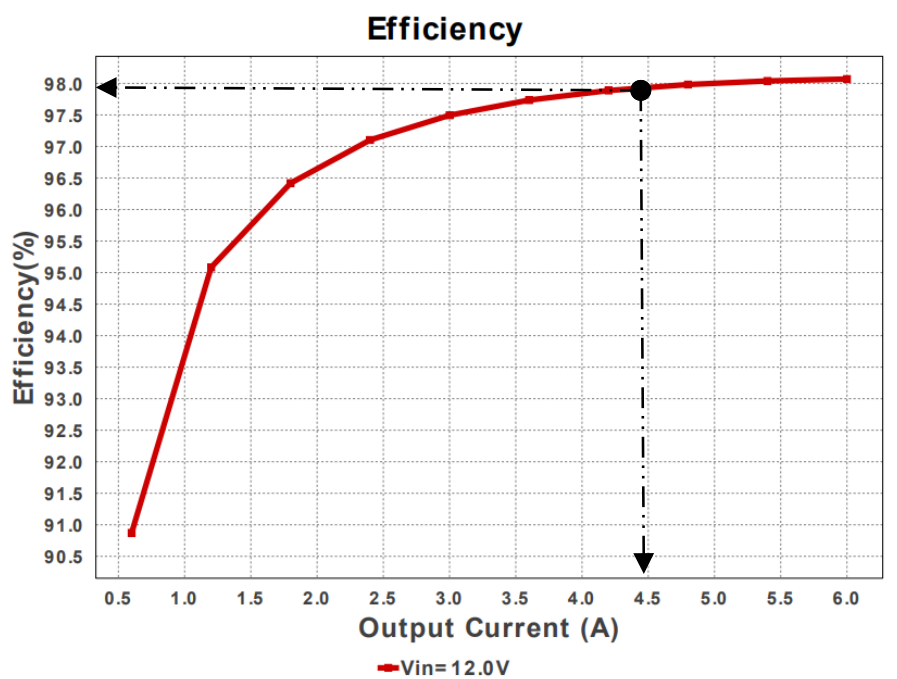

Fig. 8. Obtained efficiency regarding the output voltage level of $5 \mathrm{~V}$ (Cascade Architecture).

The output current required at the $12 \mathrm{~V}$ DC-DC converter for the $28 \mathrm{~W}$ requested by the LiDAR system and to power the $5 \mathrm{~V}$ DC-DC converter is:

$$
\text { Iout }_{12 \mathrm{~V} \text { converter }}=\frac{28 \mathrm{~W}+\frac{5 \mathrm{~W}+\frac{17 \mathrm{~W}}{E f f_{C 3.3 V}}}{E f f_{C 5 V}}}{12 \mathrm{~V}} \approx 4.24 \mathrm{~A}
$$

According to the graph displayed at Fig. 9, the expected efficiency of $12 \mathrm{~V} \mathrm{DC}-\mathrm{DC}$ converter $\left(E f f_{C 12 V}\right)$ for an output current of $4.24 \mathrm{~A}$ and an input voltage of $65 \mathrm{~V}$ (worst case) is approximately $96.25 \%$. Again, the efficiency is better for lower input voltages, namely $97.25 \%$ for an input voltage of $40 \mathrm{~V}$ and $98.7 \%$ for an input voltage of $15 \mathrm{~V}$. 


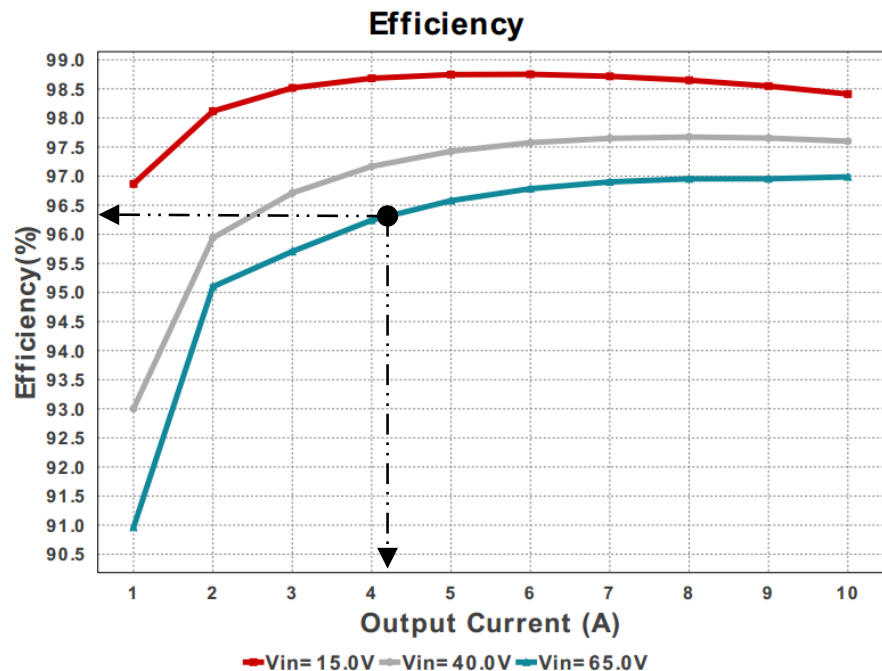

Fig. 9. Obtained efficiency regarding the output voltage level of $12 \mathrm{~V}$ (Cascade Architecture).

Therefore, the efficiency for the cascade architecture is:

$$
\eta=\frac{50 W}{\frac{5+\frac{17 W}{E f f_{C 3.3 V}}}{E f f_{C 5 V}}}=0.9467=94.67 \%
$$

\subsection{Hybrid Architecture}

In this architecture, the $5 \mathrm{~V} \mathrm{DC}$-DC converter and the $3.3 \mathrm{~V} \mathrm{DC}$-DC converter are in parallel, cascaded with the $12 \mathrm{~V}$ DC-DC converter; therefore, they have the same input of $12 \mathrm{~V}$, while the $12 \mathrm{~V}$ DC-DC converter has an input voltage range of $15 \mathrm{~V}$ to $65 \mathrm{~V}$, as illustrated in Fig. 3 (a).

According to the graph displayed at Fig. 10, the expected efficiency of the $3.3 \mathrm{~V}$ DC-DC converter $\left(E f f_{H 3.3 \mathrm{~V}}\right)$ for an output current of $5.15 \mathrm{~A}$ and an input voltage of $12 \mathrm{~V}$ is approximately $97.4 \%$. 


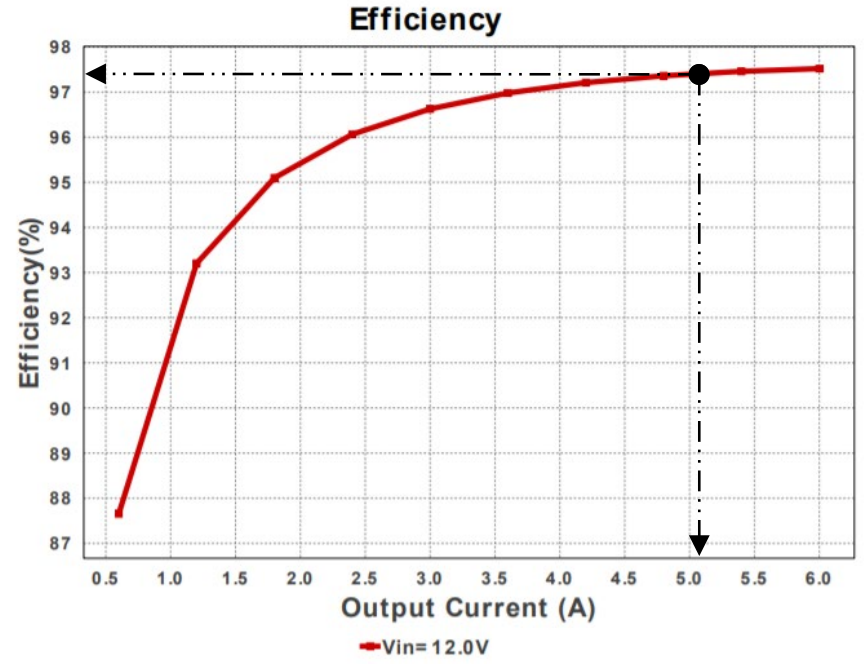

Fig. 10. Obtained efficiency regarding the output voltage level of 3.3 V (Hybrid Architecture).

According to the graph displayed at Fig. 11, the expected efficiency of the $5 \mathrm{~V}$ DC-DC converter $\left(E f f_{H S V}\right)$ for an output current of $1 \mathrm{~A}$ and an input voltage of $12 \mathrm{~V}$ is $97.4 \%$.

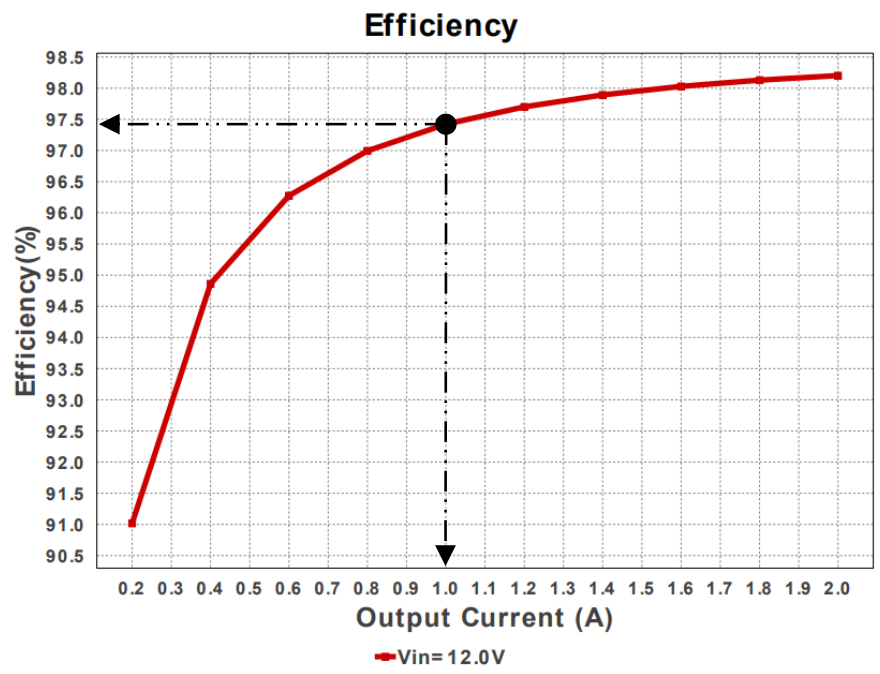

Fig. 11. Obtained efficiency regarding the output voltage level of $5 \mathrm{~V}$ (Hybrid Architecture).

The output current required at the $12 \mathrm{~V} \mathrm{DC}$-DC converter for the $28 \mathrm{~W}$ requested by the LiDAR system and to power the attached converters $(5 \mathrm{~V}$ and $3.3 \mathrm{~V})$ is:

$$
\text { Iout }_{12 \mathrm{~V} \text { converter }}=\frac{28 \mathrm{~W}+\frac{5 \mathrm{~W}}{E f f_{H 5 \mathrm{~V}}}+\frac{17 \mathrm{~W}}{E f f_{H 3.3 \mathrm{~V}}}}{12 \mathrm{~V}} \approx 4.22 \mathrm{~A}
$$


According to the graph displayed at Fig. 12, the expected efficiency of the $12 \mathrm{~V}$ DC-DC converter $\left(E f f_{H 12 V}\right)$ for an output current of $4.22 \mathrm{~A}$ and an input voltage of $65 \mathrm{~V}$ (worst case) is approximately $96.25 \%$. As in the former cases of the $3.3 \mathrm{~V}$ and $5 \mathrm{~V}$ DC-DC converters, the efficiency is better for lower input voltages, namely $97.25 \%$ for an input voltage of $40 \mathrm{~V}$ and $98.7 \%$ for an input voltage of $15 \mathrm{~V}$.

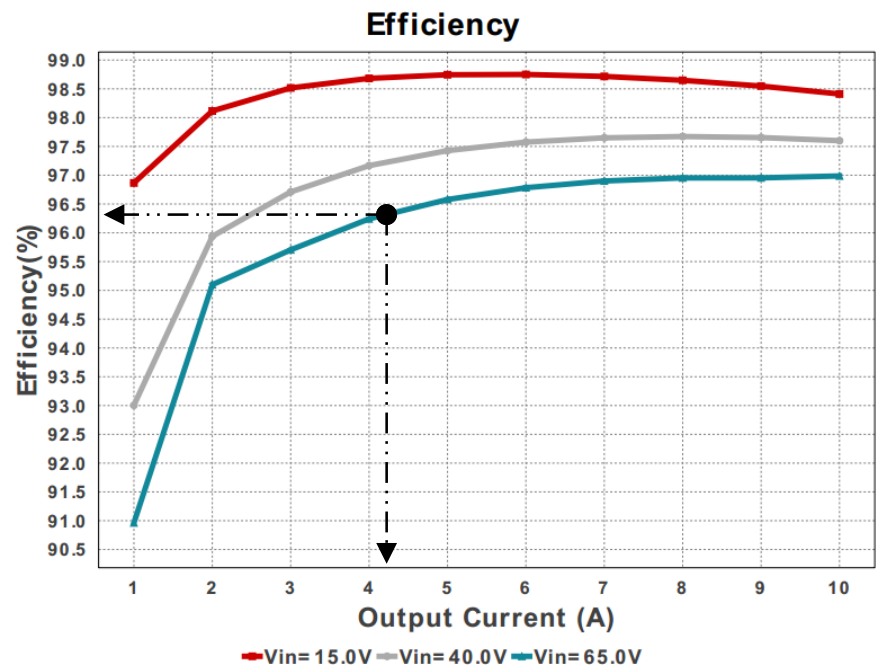

Fig. 12. Obtained efficiency regarding the output voltage level of $12 \mathrm{~V}$ (Hybrid Architecture).

Therefore, the efficiency for the hybrid architecture is:

$$
\eta=\frac{50 W}{\frac{28 W+\frac{5 W}{E f f_{H 5 V}}+\frac{17 W}{E f f_{H 3.3 V}}}{E f f_{H 12 V}}}=95.13 \%
$$

\subsection{Efficiency Comparison}

The efficiency must be as high as possible to prevent unwanted power losses and optimize the LiDAR system performance. According to the detailed study performed focusing on the efficiency of the three possible architectures, and presented in the previous items, the obtained values of efficiency for each architecture are summarized in Table 3. By comparing the three architectures for the same conditions of operation, it was possible to identify that the hybrid architecture presents the best obtained efficiency, with a value of $95.13 \%$. Nevertheless, it was also possible to analyze that the cascade architecture, with an efficiency of $94.67 \%$, is also a good alternative to the hybrid architecture for the LiDAR system, since the obtained values are very similar to the cascade architecture. The parallel architecture presents the worst efficiency with a relevant difference when compared with the other architectures, demonstrating that it is not a good alternative for a LiDAR system due to the high-efficiency required. 
Table 3. Comparison of estimated efficiencies among the architectures considered.

\begin{tabular}{|c|c|}
\hline Architecture & Efficiency \\
\hline Parallel & $88.97 \%$ \\
\hline Hybrid (a) & $95.13 \%$ \\
\hline Cascade & $94.67 \%$ \\
\hline
\end{tabular}

\section{Conclusions}

This paper presented a comparison between different DC-DC converter architectures for a LiDAR system. The architectures under comparison were: three DC-DC converters linked in a single-input multiple-output (SIMO) structure; three DC-DC converters linked in cascade; and two DC-DC converters in a SIMO structure and in cascade with the third one. The DC-DC converters under comparison in the scope of this paper are based in the synchronous buck Switched-Mode Power Supply (SMPS) topology, and with the models LM5146-Q1, LM5116 and TPS548A20.

To evaluate and compare the performance of each DC-DC converter architecture, each converter was simulated with the WEBENCH ${ }^{\circledR}$ Power Designer software in order to determine its individual efficiency. The obtained results for the considered application show that the hybrid architecture has the highest efficiency $(95.08 \%)$, considering the higher possible voltage at the input $(65 \mathrm{~V})$ and the maximum operating power of this particular LiDAR system. Taking into account that this DC-DC converter architecture accepts a wide range of input voltages and is able to provide multiple output voltages $(12 \mathrm{~V}, 5 \mathrm{~V}$, and $3.3 \mathrm{~V})$, it is the most appropriate option considering the requisites of the presented LiDAR in terms of input voltage, output voltages, and different operating power levels. Only three of the possible variant architectures were used in the comparison to demonstrate the comparison method. The same methodology could have been used considering all possible hybrid variant architectures, the final best choice (best efficiency) will depend, in a general case, on the individual efficiencies exhibited by the DC-DC converters and the required power levels associated to each specified output voltage.

\section{Acknowledgements}

This work has been supported by national funds through FCT - Fundação para a Ciência e Tecnologia within the Project Scope: UIDB/00319/2020, and also European Structural and Investment Funds in the FEDER component, through the Operational Competitiveness and Internationalization Programme (COMPETE 2020) [Project $n^{\circ}$ 037902; Funding Reference: POCI-01-0247-FEDER-037902]. 


\section{References}

1. Anton Manfreda, Klara Ljubi, Aleš Groznik, "Autonomous vehicles in the smart city era: An empirical study of adoption factors important for millennials", International Journal of Information Management, 2019, 102050, ISSN 0268-4012.

2. M. Yoshioka, N. Suganuma, K. Yoneda and M. Aldibaja, "Real-time object classification for autonomous vehicle using LIDAR," 2017 International Conference on Intelligent Informatics and Biomedical Sciences (ICIIBMS), Okinawa, 2017, pp. 210-211, doi: 10.1109/ICIIBMS.2017.8279696.

3. M. Gerber, J. A. Ferreira, I. W. Hofsajer, and N. Seliger, "High density packaging of the passive components in an automotive DC/DC converter", IEEE Trans. Power Electron., vol. 20, no. 2, pp. 268-275, 2005.

4. T. Van Breussegem, M. Wens, J. M. Redouté, E. Geukens, D. Geys, and M. Steyaert, "A DMOS integrated $320 \mathrm{~mW}$ capacitive $12 \mathrm{~V}$ to $70 \mathrm{~V}$ DC/DC-converter for LIDAR applications", in 2009 IEEE Energy Conversion Congress and Exposition, ECCE 2009, 2009, pp. 3865-3869.

5. J. Yang, G. Zhou, X. Yu and W. Zhu, "Design and Implementation of Power Supply of High-Power Diode Laser of LiDAR Onboard UAV," 2011 International Symposium on Image and Data Fusion, Tengchong, Yunnan, China, 2011, pp. 1-4, doi: 10.1109/ISIDF.2011.6024309.

6. X. Cui, C. Keller and A. Avestruz, "Cycle-by-Cycle Digital Control of a Multi-Megahertz Variable-Frequency Boost Converter for Automatic Power Control of LiDAR," 2019 IEEE Energy Conversion Congress and Exposition (ECCE), Baltimore, MD, USA, 2019, pp. 702711, doi: 10.1109/ECCE.2019.8913074.

7. A. Bubovich, "The comparison of different types of DC-DC converters in terms of lowvoltage implementation," 2017 5th IEEE Workshop on Advances in Information, Electronic and Electrical Engineering (AIEEE), Riga, Latvia, 2017, pp. 1-4, doi: 10.1109/AIEEE.2017.8270560.

8. Jian Fu, Bo Zhang, Dongyuan Qiu and Wenxun Xiao, "A novel single-switch cascaded DCDC converter of Boost and Buck-boost converters," 2014 16th European Conference on Power Electronics and Applications, Lappeenranta, Finland, 2014, pp. 1-9, doi: 10.1109/EPE.2014.6910723.

9. S. Chakraborty, H. N. Vu, M. M. Hasan, D. D. Tran, M. El Baghdadi, and O. Hegazy, 'DCDC converter topologies for electric vehicles, plug-in hybrid electric vehicles and fast charging stations: State of the art and future trends', Energies, vol. 12, no. 8, 2019.

10. M. S. Bhaskar Ranjana, N. S. Reddy and R. K. Pavan Kumar, "Non-isolated dual output hybrid DC-DC multilevel converter for photovoltaic applications," 2014 2nd International Conference on Devices, Circuits and Systems (ICDCS), Combiatore, India, 2014, pp. 1-6, doi: 10.1109/ICDCSyst.2014.6926197.

11. R. C. Chang, W. Chen, C. Siao and H. Wu, "Low-complexity SIMO buck-boost DC-DC converter for gigascale systems," 2016 IEEE International Symposium on Circuits and Systems (ISCAS), Montreal, QC, 2016, pp. 614-617, doi: 10.1109/ISCAS.2016.7527315.

12. R. KIGUCHI and Y. NISHIDA, "Boost DC-DC Converter Cascade System for High BoostRate Application," 2018 International Conference on Smart Grid (icSmartGrid), Nagasaki, Japan, 2018, pp. 283-286, doi: 10.1109/ISGWCP.2018.8634483.

13. Texas Instruments, "LM5146-Q1 100-V Synchronous Buck DC/DC Controller With Wide Duty Cycle Range." [Online]. Available: https://www.ti.com/product/LM5146-Q1.

14. Texas Instruments, "6-100V Wide Vin, Current Mode Synchronous Buck Controller." [Online]. Available: https://www.ti.com/product/LM5116. 
15. Texas Instruments, " $1.5 \mathrm{~V}$ to $20 \mathrm{~V}$ ( $4.5 \mathrm{~V}$ to $25 \mathrm{~V}$ Bias) Input, $15 \mathrm{~A}$ SWIFTTM Synchronous Step-Down Converter" [Online]. Available: https://www.ti.com/product/TPS548A20.

16. J. Sreedhar and B. Basavaraju, "Design and analysis of synchronous Buck converter for UPS application," 2016 2nd International Conference on Advances in Electrical, Electronics, Information, Communication and Bio-Informatics (AEEICB), Chennai, India, 2016, pp. 573579, doi: 10.1109/AEEICB.2016.7538356.

17. H. M. Rashid, "DC-DC Converters", in Power Electronics Handbook, Acaddemic Press, pp. 211-223, 2003.

18. Z. Iqbal, U. Nasir, M. T. Rasheed and K. Munir, "A comparative analysis of synchronous buck, isolated buck and buck converter," 2015 IEEE 15th International Conference on Environment and Electrical Engineering (EEEIC), Rome, Italy, 2015, pp. 992-996, doi: 10.1109/EEEIC.2015.7165299.

19. Texas Instruments, "WEBENCH ${ }^{\circledR}$ Power Designer" [Online]. Available: https://www.ti.com/design-resources/design-tools-simulation/webench-power-designer.html. 